\title{
Achalasia like disorder of the oesophagus in von Recklinghausen's neurofibromatosis
}

\author{
P N FOSTER, MARGARET STEWART, J S LOWE, \\ AND MICHAEL ATKINSON \\ From the University Hospital, Queen's Medical Centre, Nottingham
}

SUMMARY The association of achalasia like disorder of the oesophagus with von Recklinghausen's neurofibromatosis to our knowledge not previously reported is described in a 56 year old man who also had bladder dysfunction. At necropsy the oesophageal myenteric plexus showed ganglion cell depletion with nerve fibre hyperplasia probably the result of Schwann cell hyperplasia. We suggest that the disturbances of oesophageal and bladder function were a consequence of involvement of the autonomic nervous system by neurofibromatosis.

Neurofibromatosis has been estimated to be present in one person in 3000 of the population at birth and $25 \%$ of those with the disease have been reported to have alimentary involvement.' Most of these have neoplasm, predominantly neurofibroma with some leiomyoma, but megacolon from involvement of the autonomic nervous system, by neurofibromatosis, is a well established entity. We report a patient with an achalasia like disorder of the oesophagus and with bladder dysfunction complicating hereditary neurofibromatosis.

\section{Case report}

A 56 year old man with neurofibromatosis (Fig. 1) presented in acute renal failure as a result of urinary retention with a blood urea of $73 \mathrm{mmol} / \mathrm{l}$, potassium $7.6 \mathrm{mmol} / \mathrm{l}$, sodium $129 \mathrm{mmol} / \mathrm{l}$. His mother and a maternal stepbrother also suffered from neurofibromatosis. Catheterisation of the bladder resulted in the drainage of $4450 \mathrm{ml}$ urine and the blood urea and electrolytes returned to normal concentrations. Myelography excluded cord compression. An intravenous urogram revealed normal sized kidneys and no pelvicalyceal or ureteric dilatation. At cystoscopy the bladder was seen to be trabeculated and had many diverticula; the prostate appeared small and the serum acid phosphatase $(7 \mathrm{U} / \mathrm{l})$ and tartrate labile fraction (2U/l) were normal. He subsequently underwent transurethral resection of the prostate.

Address for correspondence: Dr P N Foster. (iastrointestinal Unit. The General Intirmary. Great George Strect. Ieceds I SI 3EX.

Received for publication 16 April 1987
In addition to his immediate genitourinary problems, the patient mentioned that for several years he had had difficulty in swallowing both liquids and solids and occasionally he regurgitated food that he had eaten as long as 48 hours previously. Chest radiograph showed an air containing mediastinal mass. A barium swallow (Fig. 2) showed a grossly dilated oesophagus filled with food residue, and a smooth, narrowed, distal segment suggestive of achalasia. Fibreoptic endoscopy revealed a dilated hypotonic oesophagus containing food debris; the cardia was tightly closed but admitted the instrument (GIFT Olympus) easily.

Manometric studies showed that swallowing produced simultaneous, single waves of low amplitude

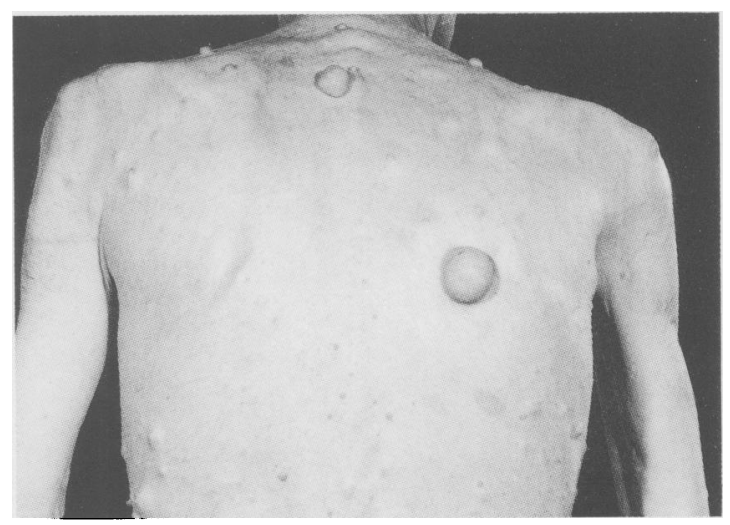

Fig. 1 Patient's cutaneous stigmata of neurofibromatosis. 


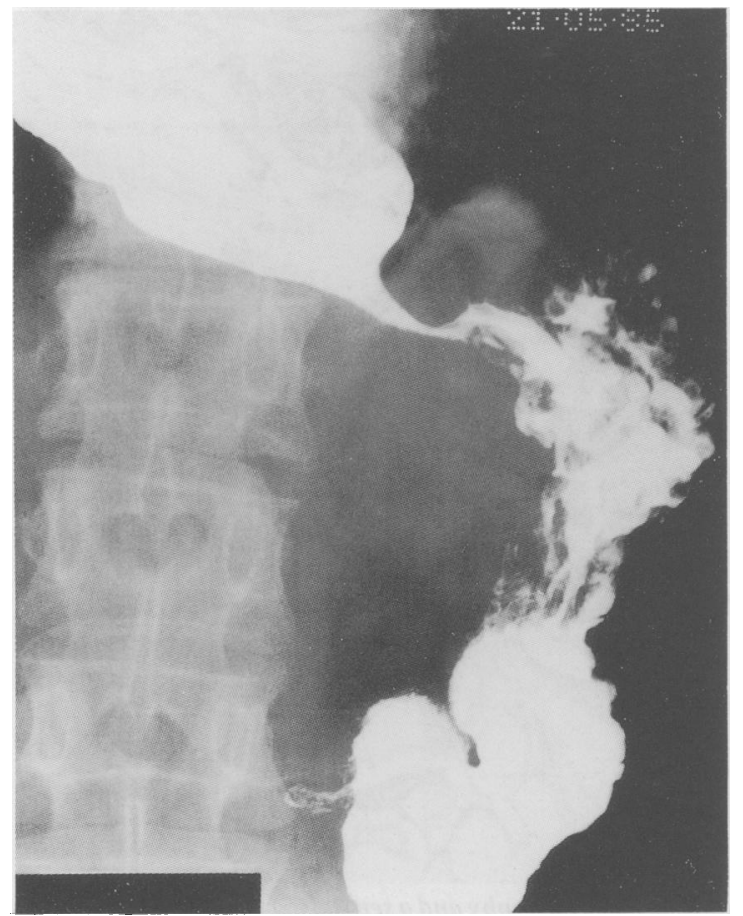

Fig. 2 Barium swallow which shows a dilated oesophagus containing food residue with a smooth, narrowed distal segment suggestive of achalasia.

throughout the oesophagus and no relaxation of the lower oesophageal sphincter. The resting lower oesophageal sphincter pressure was $25 \mathrm{~cm} \mathrm{H}_{2} \mathrm{O}$. A diagnosis of achalasia was made and the patient underwent pneumatic bag dilatation of the cardia with considerable immediate relief of his dysphagia.

Because of the bladder and oesophageal dysfunction evidence of an autonomic neuropathy was sought: there was no postural hypotension and pulse rate variability with deep respiration was normal. A search was made for involvement of the large bowel by barium enema which showed a few diverticula but no other abnormality.

Three weeks after discharge from hospital the patient was readmitted having collapsed at home. Examination revealed that he was deeply unconscious with signs of brain stem dysfunction. A computerised tomographic brain scan was suggestive of a pontine infarct. The patient died 20 hours after admission.

\section{NECROPSY FINDINGS}

External examination showed multiple cutaneous neurofibromata.

The macroscopic appearances of the oesophagus were typical of achalasia with dilatation maximal in the middle third and thickening of the wall. No stricture or neurofibromata were visible.

Histological examination of the oesophagus showed stratified squamous epithelium, submucosal fibrosis and a mild chronic inflammatory infiltrate. The striated muscle of the upper one third showed evidence of neurogenic atrophy (Fig. 3) whilst the smooth muscle in the lower two thirds was hypertrophic. Very few ganglion cells were seen in the myenteric plexus and only four were identified in 22 sections taken at $2 \mathrm{~cm}$ intervals throughout the length of the oesophagus. The nerves of the myenteric plexus appeared enlarged because of Schwann cell and fibroblast proliferation (Fig. 4).

The serosal nerves, including the vagi, were also enlarged many showing perineural fibrosis and others a plexiform diffuse form of neurofibromatosis (Fig. 5).

The remainder of the gastrointestinal tract was macroscopically normal. Normal numbers of ganglion cells were present in the wall of the rectum and stomach. Small neurofibromata were microscopically identified in the gastric serosa. The only nodular neurofibroma grossly identified on internal examination was in the abdominal para-aortic region. There was bilateral mild hydronephroses and hydroureters, and the bladder was enlarged with formation of diverticula. Histological examination showed extensive plexiform neurofibromatosis involving nerves around the base of the bladder and the prostate gland (vesical and prostatic plexuses).

The brain and spinal cord had detailed neuropathological examination. The macroscopic appearances were normal, but microscopic examination showed terminal hypoxic neuronal cell death in the hippocampus and the cerebellum. No pontine infarction was seen. Neuronal cell counts in the dorsal motor nuclei of the vagi were within normal limits although there was mild reactive gliosis suggesting that there may have been a minor degree of neuronal cell death.

There were no further relevant findings in the other viscera.

\section{Discussion}

The radiological and manometric features together with the histological oesophageal findings of hypoganglionosis, fibrosis with a chronic inflammatory cell infiltrate, and smooth muscle hypertrophy, found in this patient are typical of achalasia of the cardia. The striking enlargement of myenteric nerve fibres and the neurogenic atrophy of oesophageal striated muscle fibres, however, are not features of idiopathic achalasia. To our knowledge this is a hitherto unreported association of von Recklinghausen's 


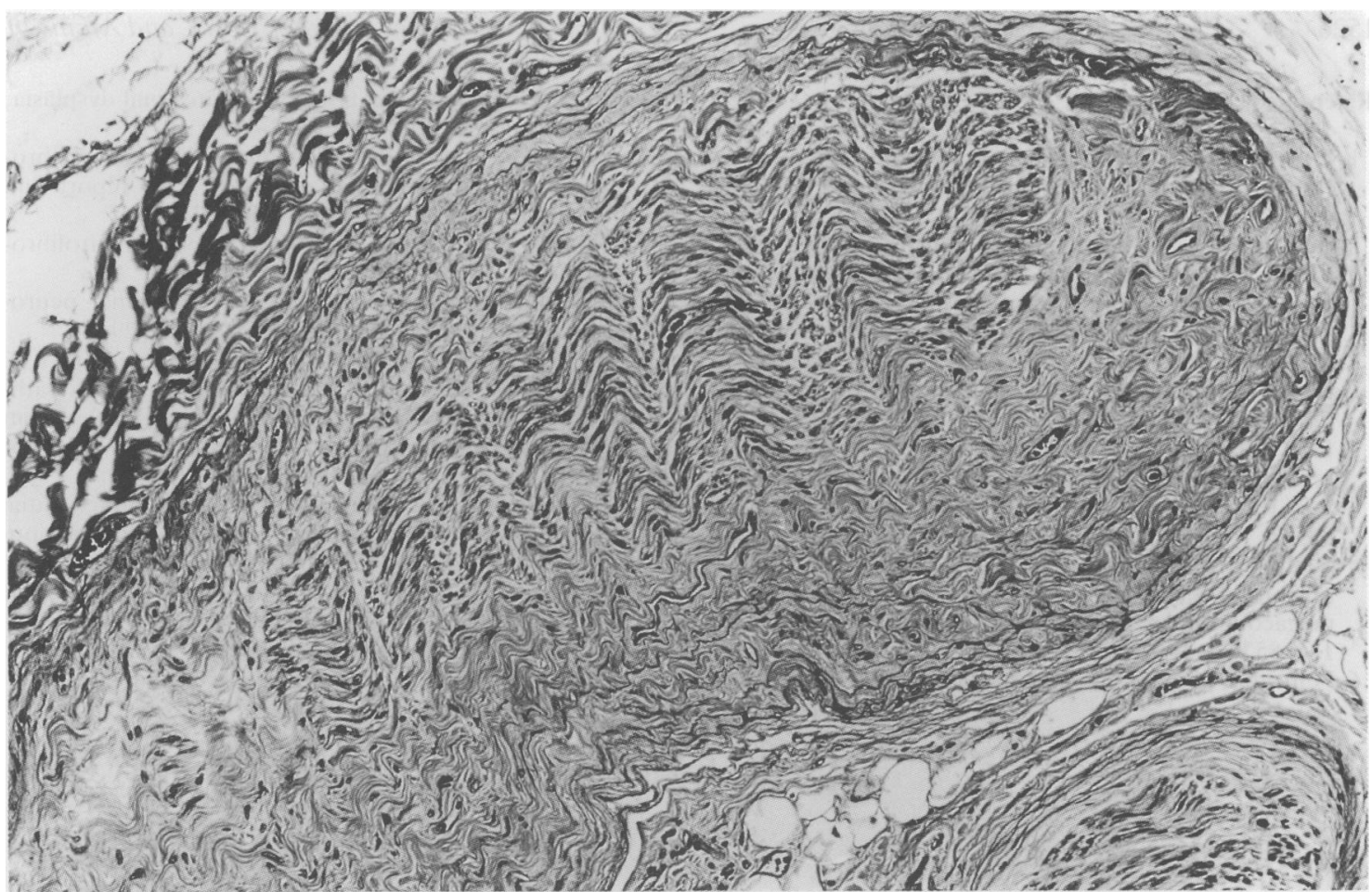

Fig. 5 Serosal nerve showing partial involvement by neurofibromatosis. ( $H$ and $E$ ).

neurofibromatosis. In addition this patient had bladder dysfunction in association with plexiform neurofibromatosis. The likelihood that the disturbances of oesophageal and bladder function were caused by the neurofibromatosis gains support from reports of autonomic dysfunction involving the colon $^{-1-}$ and bladder ${ }^{7}$ in patients with von Recklinghausen's disease.

Where megacolon is associated with neurofibromatosis, enlargement of the nerves of the myenteric plexus in the colon is a common feature and in one case which came to necropsy, ${ }^{5}$ these changes were noted throughout the gastrointestinal tract, including the oesophagus. Enlargement of myenteric nerve fibres was noted in the oesophagus of our patient. A recent review states that hypertrophy of the myenteric plexus occurs in $50 \%$ of patients with von Recklinghausen's disease. Functional gastrointestinal disturbance is less common, however, although constipation sometimes associated with megacolon, occurs in about $10 \%$ of patients with neurofibromatosis."

Hypoganglionosis in the oesophageal myenteric plexus is generally recognised to be a feature of achalasia although the absolute counts vary widely,"' and in our patient was especially severe. Ganglion cells in the colon of patients with neurofibromatosis and megacolon are either present in normal ${ }^{3}$ or decreased $^{\text {ith }}$ numbers and Feinstat et al" emphasised that the reduction may be patchily distributed. Such marked hypoganglionosis, however, as seen in the oesophagus of our patient has not been described previously. Thus it seems unlikely that the hypoganglionosis is entirely explicable on the basis of myenteric plexus enlargement which was present in our patient and those cases of megacolon previously reported. The observation of involvement of serosal nerves with neurofibromatosis and associated neurogenic atrophy of oesophageal striated muscle raises the possibility that the hypoganglionosis may have resulted from trans-synaptic degeneration, although this is a doubtful entity in the autonomic nervous system. Another possibility is that the hypoganglionosis results from the abnormal embryological development of neural crest cells, which give rise to cranial and spinal sensory ganglia, sympathetic and parasympathetic plexuses, Schwann cells, and many other tissues, as proposed by Bolande."

This case report highlights the fact that significant disturbances of gastrointestinal motility occur in neurofibromatosis as well as the better recognised association of gastrointestinal tumours." " The mechanism underlying the abnormal motility is not certain. 


\section{References}

1 Davis GB. Berk RN. Intestinal neurofibromas in von Recklinghausen's disease. Am J Gastroenterol 1973; 60: 41()$-4$.

2 Staple TW, McAlister WH, Anderson MS. Plexiform neurofibromatosis of the colon simulating Hirschsprung's disease. Am J Roentgenol 1964; 91: $840-5$.

3 Ternberg JL, Winters K. Plexiform neurofibromatosis of the colon as a cause of congenital megacolon. Am J Surg 1965; 109: 66.3-5.

4 Phat VN, Seleur A, Da M, et al. Primary myenteric plexus alterations as a cause of megacolon in von Recklinghausen's disease. Pathol Biol 1980; 18: $585-8$.

5 Saul RA, Sturner RA. Burger PL. Hyperplasia of the myenteric plexus. Its association with early infantile megacolon and neurofibromatosis. Am J Dis Child 1982; 136: $8.52-4$.

6 Feinstat T, Tesluk H. Schuffler MD, et al. Megacolon and neurofibromatosis: a neuronal intestinal dysplasia. Gastroenterology 1984: 86: 1573-9.

7 Clark SS. Martlett MM. Prudencio RF. Neurofibromatosis of the bladder in children: case report and literature review. J Urol 1977: 118: 6.54-6.

8 Riccardi VM. Von Recklinghausen's neurofibromatosis. N Engl J Med 1981: 305: 1617-27.

9 Petersen JM, Ferguson DR. Gastrointestinal neurofibromatosis. J Clin (iastroenterol 1984; 6: 529-34

10 Misiewicz JJ. Waller SL, Anthony PP. Gummer JWP. Achalasia of the cardia: pharmacology and histopathology of isolated cardiac sphincteric muscle from patients with and without achalasia. () J Med 1969; 38: 17-30.

11 Bolande RP. Neurofibromatosis - the quintessential neurocristopathy. Pathogenic concepts and relationships. Adv' Neurol 1981: 29: 67-75.

12 Hochberg FH, Dasilva AB, Galdabim J, Richardson EP. Gastrointestinal involvement in von Recklinghausen's neurofibromatosis. Neurology 1976; 24: $1144-51$ 